\title{
Extramedullary plasmacytoma in the carotid space: Expanding the differential diagnosis
}

\author{
Sneha Satish Deshpande, Shubhada Kane', Supreeta Arya \\ Departments of Radiodiagnosis and ${ }^{1}$ Pathology, Tata Memorial Hospital, Mumbai, Maharashtra, India \\ Correspondence: Dr. Supreeta Arya, Department of Radiodiagnosis, Tata Memorial Hospital, Mumbai, Maharashtra, India. \\ E-mail: supreeta.arya@gmail.com
}

\begin{abstract}
Plasma cell neoplasms have been classified into various types, with a range of clinical and radiological presentations. Extramedullary plasmacytoma (EMP) is a subset of plasma cell neoplasms which presents as an isolated non-osseous soft tissue mass. Though carotid space neoplasms are commonly encountered, EMP in the carotid space is rare and seldom considered in the initial differential diagnosis of a carotid space mass. These tumors can be treated by surgery or radiotherapy. On the other hand, the commonly encountered tumors in the carotid space are treated surgically. Also, it is mandatory to exclude multiple myeloma in the patients presenting with EMP. Hence, accurate and early diagnosis has therapeutic and prognostic implications. We report a rare case of EMP of the carotid space, describing the imaging features and the differential diagnoses with clues pointing to this rare entity.
\end{abstract}

Key words: Carotid space; extramedullary plasmacytoma; magnetic resonance imaging

\section{Introduction}

Neoplasms in the carotid space are frequently encountered entities in a busy oncologic practice. These include a group of diverse tumors whose management may differ significantly. However, there is an overlap between the clinical presentations of these tumors. Imaging is vital in the workup of these tumors. We herein report the imaging features of a rare case of extramedullary plasmacytoma (EMP) in the carotid space.

\section{Case Report}

A66-year-old male presented with a solitary painless swelling in the right parotid region since 2 months and dysphagia since 1 month. He denied associated dysphonia or dyspnea.

\begin{tabular}{|l|l|}
\hline \multicolumn{2}{|c|}{ Access this article online } \\
\hline Quick Response Code: & \\
\hline & Website: \\
\hline & www.ijri.org \\
\cline { 2 - 3 } & DOI: \\
\hline
\end{tabular}

His past medical history was unremarkable. On physical examination, a non-tender fixed mass was noted in the right posterior triangle of the neck, extending posteriorly upto the cervical vertebrae. Oropharyngeal examination revealed a mucosal bulge on the right lateral pharyngeal wall.

Multi-planar magnetic resonance imaging (MRI) using a 1.5 Tesla GE Signa HDxt scanner (GE Healthcare, Milwaukee, United States) revealed an $8.2 \times 9.3 \times 10 \mathrm{~cm}$ sized mass, with the epicenter in the right carotid space. It was seen to displace the carotid sheath anteriorly. The mass was isointense to muscle on T1-weighted (T1W) images [Figure 1A] and heterogeneously hyperintense on T2-weighted (T2W) images [Figure 1B]. It showed heterogeneous moderate post-contrast enhancement [Figure 2]. There was no evidence of calcification or necrosis within the mass. Medially, the right prevertebral muscles were infiltrated and the anterior cortices of the adjacent C2-C5 vertebral bodies were eroded. Extension through the neural foramina was seen. Vertebral artery was also encased. However, there was no radiological evidence of spinal cord compression. Further extension and invasion of the posterior paraspinal muscles was also observed [Figures 1 and 2]. The right parotid gland and masticator muscles were not involved. No cervical lymphadenopathy was noted. 
Computed Tomography (CT) using GE Lightspeed VFX 16 (GE Healthcare, Milwaukee, United States) was performed, which corroborated these findings, delineating the cervical vertebral erosion well. It also demonstrated focal erosion of the posterior border of the mandible at the anterior limit of the mass [Figure 3].

Tru-cut biopsy of the mass showed diffuse infiltrate of neoplastic plasma cells in soft tissue with vascular stroma [Figure 4A]. On immunohistochemistry, tumor cells showed membrane positivity with CD138 [Figure 4B]. They were negative for CD3, CD20, cytokeratin, CD56, and cyclinD1. Tumor was lambda light chain immunonegative [Figure 4C], but expressed kappa light chain on immunochemistry [Figure 4D]. A diagnosis of EMP was offered on histopathologic examination.

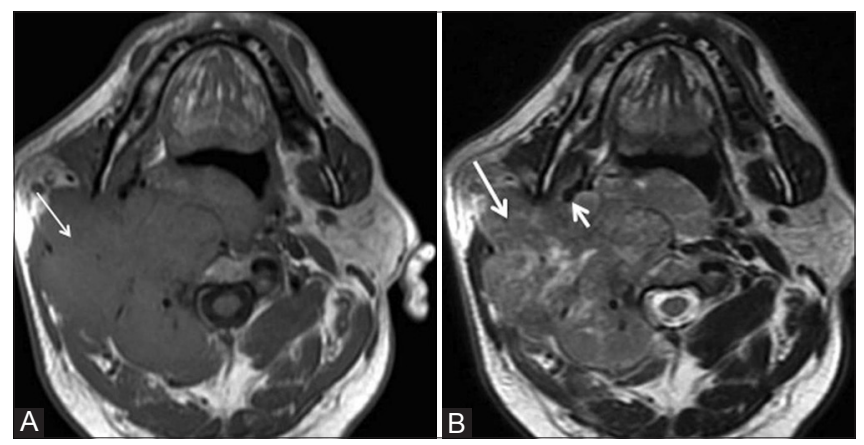

Figure 1 (A and B): (A) Axial T1W MRI reveals an ill-defined mass isointense to muscle with epicenter in the right carotid space (arrow) (B) Axial T2W MRI shows an ill-defined heterogeneously hyperintense mass (long arrow) displacing the right carotid sheath anteriorly (short arrow)

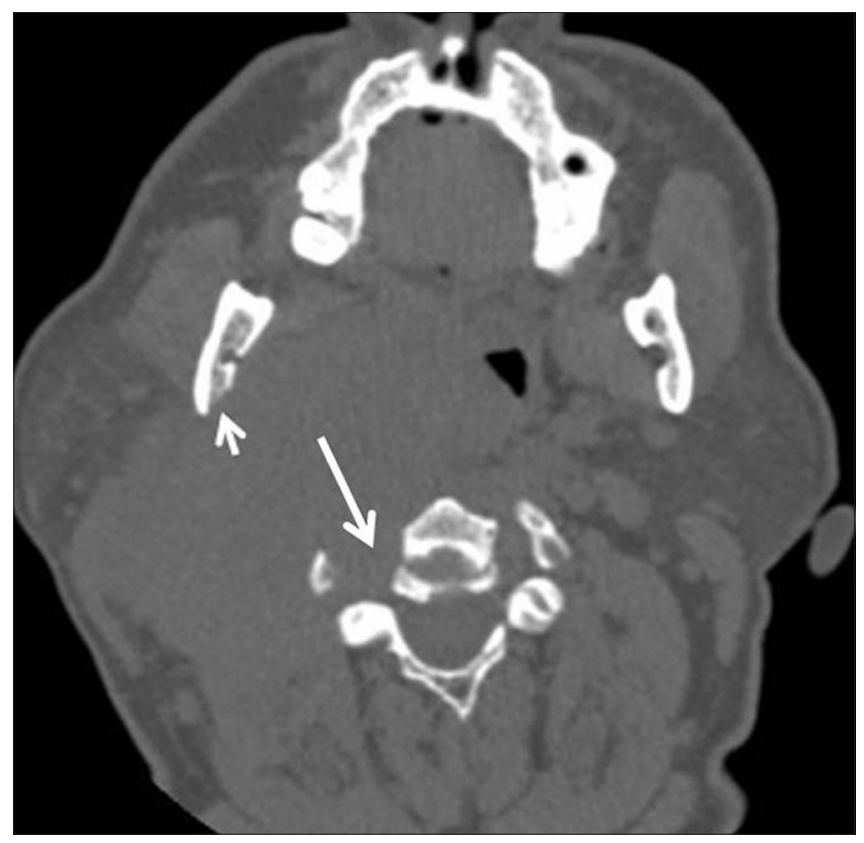

Figure 3: Axial bone window CT image showing cervical vertebral erosion due to the carotid space mass (long arrow). Also seen is focal mandibular erosion (short arrow)
The patient underwent complete workup for myeloma, and underlying multiple myeloma with extramedullary dissemination was ruled out.Our case was treated with radiotherapy. However, follow-up of our case revealed conversion into multiple myeloma after 13 months of initial diagnosis.

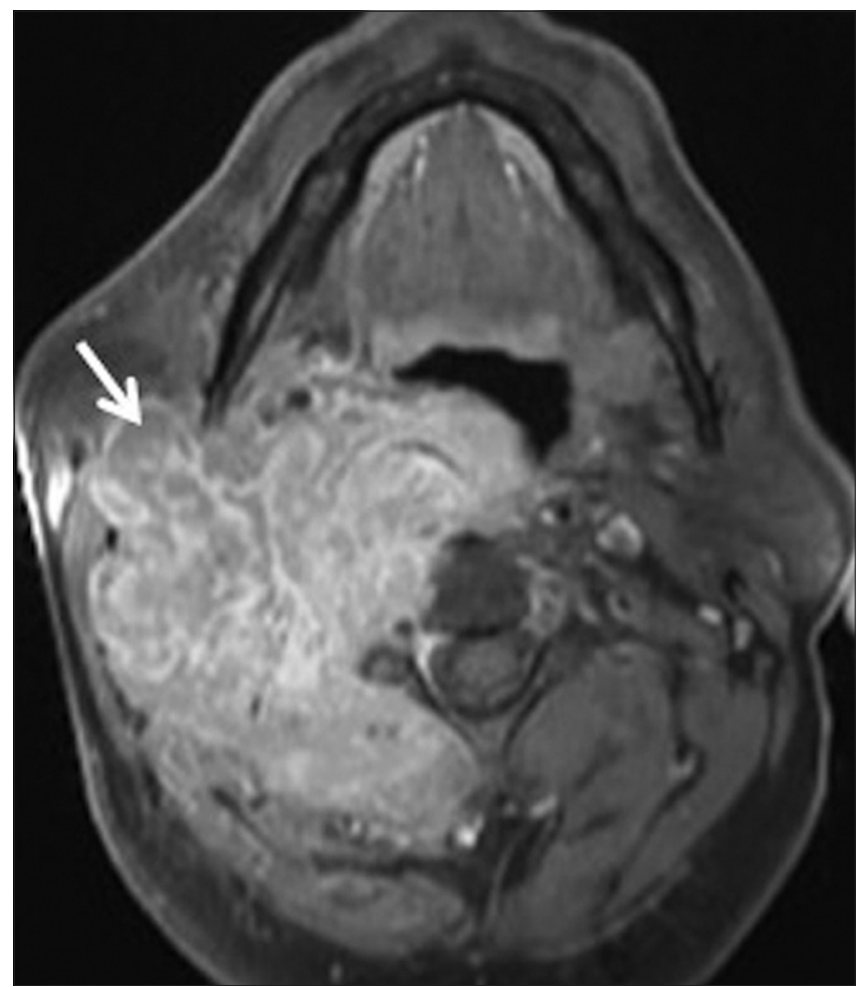

Figure 2: Post gadolinium fat-saturated T1W axial MRI showing infiltrating margins and heterogeneous moderate enhancement in the mass without necrosis (arrow)

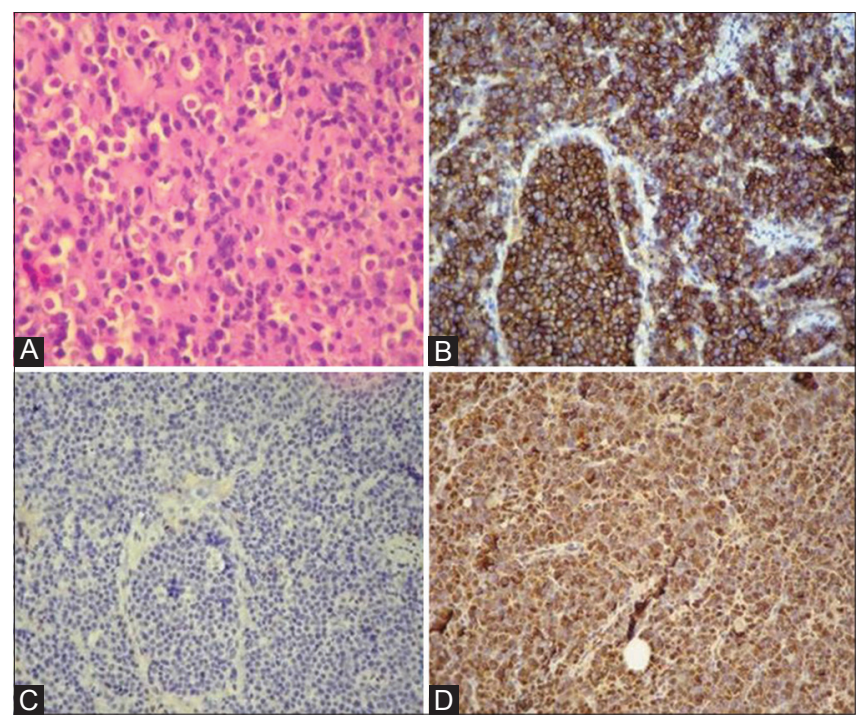

Figure 4 (A-D): (A) Tru-cut biopsy shows diffuse infiltrate of neoplastic plasma cells (B) On immunohistochemistry, the tumor cells show membrane positivity with CD138 (C) The tumor is lambda light chain immunonegative and (D) expresses kappa light chain on immunochemistry 


\section{Discussion}

Dalrymple and Bence Jones were the first to describe the plasma cell neoplasms in 1846, classifying them as follows: (1) multiple myeloma, (2) EMP, and (3) the solitary plasma cell tumors of the bone. ${ }^{[1]}$ In 2002, the International Myeloma Working Group ${ }^{[2]}$ defined the criteria for primary EMPs as: (1) absence of M-protein in serum and/or urine, (2) extramedullary tumor of clonal plasma cell, (3) normal bone marrow, (4) normal skeletal survey, and (5) no related organ or tissue impairment. ${ }^{[2]}$ This case fulfilled all these criteria. EMPs comprise about $4 \%$ of all plasma cell tumors. Nearly $80 \%$ of these are found in the upper aerodigestive tract, predominantly in the head and neck, presenting as submucosal masses in the nasal cavity, paranasal sinuses, and the nasopharynx. ${ }^{[2-4]}$ EMPs arising in non-submucosa related areas including the carotid space are rare.

The carotid space or retrostyloid parapharyngeal space is located posteriorly, separated from the prestyloid parapharyngeal space by the tensor vascular styloid fascia. Figure 5 shows the relation of carotid space to other spaces of the suprahyoid neck. Table 1 discusses the contents and differential diagnoses of carotid space lesions in detail. Radiologically, the usual differential diagnoses of carotid space masses are schwannomas, paragangliomas, neurofibromas, metastatic or tuberculous lymphadenopathy, rarely extracranial meningiomas and lymphomas [Figures 6-10]. However, schwannomas, paragangliomas, neurofibromas, and extracranial meningiomas are well-defined masses which usually do not cause bone erosion or muscle invasion. Metastatic lymphadenopathy, even from an unknown primary, is usually seen at multiple levels and vertebral erosion is infrequent. Tuberculous adenopathy is seen as matted nodal masses with multiple necrotic areas with or without abscess formation. Lymphomas present as well-defined homogenously enhancing nodal masses, with no appreciable pre-treatment necrosis. They rarely cause bone erosion except when aggressive varieties

Table 1: Carotid space: Contents and differential diagnoses

\begin{tabular}{|c|c|c|c|}
\hline Contents & Lesion & & Imaging tips \\
\hline \multirow{3}{*}{$\begin{array}{l}\text { Nerves } \\
\text { IX-XII nerves usually located posteriorly and } \\
\text { masses from these displace the vessels anteriorly } \\
\text { Sympathetic plexus located medially and the } \\
\text { vessels displaced anteriorly, laterally, or less } \\
\text { frequently posteriorly }\end{array}$} & \multicolumn{2}{|l|}{ Schwannoma (common) } & $\begin{array}{l}\text { Well-defined non-infiltrative mass; hypovascular and shows } \\
\text { delayed persistent enhancement (enhances after } 2 \text { min); larger } \\
\text { tumors show necrosis; rarely could display calcification }\end{array}$ \\
\hline & \multicolumn{2}{|l|}{ Neurofibroma (less common) } & $\begin{array}{l}\text { Well-defined non-infiltrative mass; homogenous with decreased } \\
\text { CT density and minimal post-contrast enhancement (high lipid } \\
\text { content and low cellularity) }\end{array}$ \\
\hline & \multicolumn{2}{|l|}{ Extracranial meningioma (rare) } & $\begin{array}{l}\text { Well-defined non-infiltrative mass; mildly hyperdense on plain CT; } \\
\text { may show calcification; } \\
\text { iso- to hypointense on T2W; homogenous strong post-contrast } \\
\text { enhancement on CT and MRI; may show intracranial component } \\
\text { in the posterior fossa }\end{array}$ \\
\hline $\begin{array}{l}\text { Paraganglionic tissue } \\
\text { Located posterior to vessels and displaces } \\
\text { vessels anteriorly/anterolaterally }\end{array}$ & \multicolumn{2}{|l|}{ Paraganglioma } & $\begin{array}{l}\text { Well-defined non-infiltrative mass; early striking enhancement } \\
\text { and rapid washout } \\
\text { Homogenous when small; nonhomogenous when large; } \\
\text { MRI could show hyperintense slow flow areas and dark flow } \\
\text { voids (salt and pepper appearance) }\end{array}$ \\
\hline Internal carotid artery & \multicolumn{2}{|l|}{$\begin{array}{l}\text { Aneursym/pseudoaneursym } \\
\text { Dissection/thrombosis }\end{array}$} & Tubular configuration and origin from vessel \\
\hline Internal jugular vein & \multicolumn{2}{|c|}{ Thrombosis/thrombophlebitis/ectasia } & Tubular configuration and origin from vessel \\
\hline \multirow[t]{4}{*}{ Nodes (outside sheath) } & Metastatic nodes & & $\begin{array}{l}\text { Primary usually identified; usually multiple, bone erosion } \\
\text { infrequent; illdefined with muscle and vessel invasion when } \\
\text { extracapsular spread is present }\end{array}$ \\
\hline & Tuberculous nodes & & $\begin{array}{l}\text { Matted nodal masses often with caseous necrosis; maybe at } \\
\text { multiple levels; constitutional symptoms }\end{array}$ \\
\hline & \multirow[t]{2}{*}{ Miscellaneous } & $\begin{array}{l}\text { Extranodal } \\
\text { lymphoma }\end{array}$ & $\begin{array}{l}\text { Non-infiltrative homogenously enhancing mass; bone erosion rare } \\
\text { Exception- Aggressive T cell lymphoma can show ill-defined } \\
\text { margins, necrosis, and bone erosion }\end{array}$ \\
\hline & & EMP & $\begin{array}{l}\text { Solid homogenous or mildly heterogeneously enhancing mass; } \\
\text { infiltrative with bone erosion, muscle and vessel invasion } \\
\text { Multiple vertebral erosions with a disproportionate large soft } \\
\text { tissue component favor a non-osseous origin }\end{array}$ \\
\hline Spread from adjacent spaces & $\begin{array}{l}\text { Pharynx (tumor/abscess) } \\
\text { Parotid space (tumor/abscess) } \\
\text { Vertebrae (tumor/tuberculosis) }\end{array}$ & & $\begin{array}{l}\text { Epicenter not in the carotid space } \\
\text { Tuberculosis may be associated with paraspinal abscess }\end{array}$ \\
\hline
\end{tabular}

MRI: Magnetic resource imaging, EMP: Extramedullary plasmacytoma, CT: Computed tomography, T2W: T2-weighted 


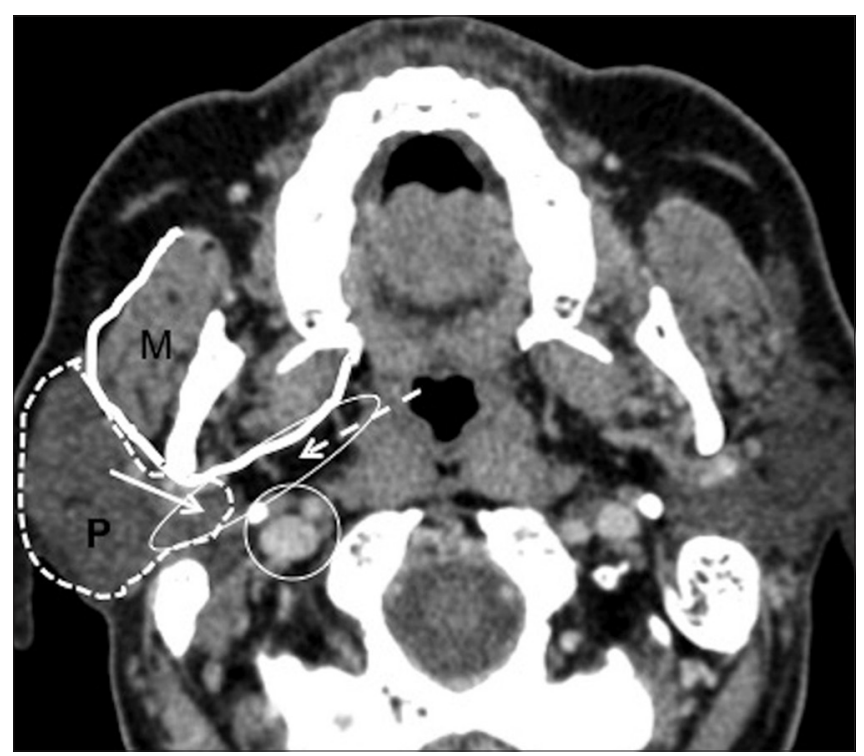

Figure 5: Carotid space and relations. Axial CT section showing dotted lines enclosing parotid space containing parotid gland $(P)$, masticator space M (solid outline), carotid space (circle) containing the internal carotid artery (medial) and internal jugular vein (lateral), prestyloid parapharyngeal space (ellipse) containing parapharyngeal fat (dashed arrow) and deep lobe of parotid (solid arrow)

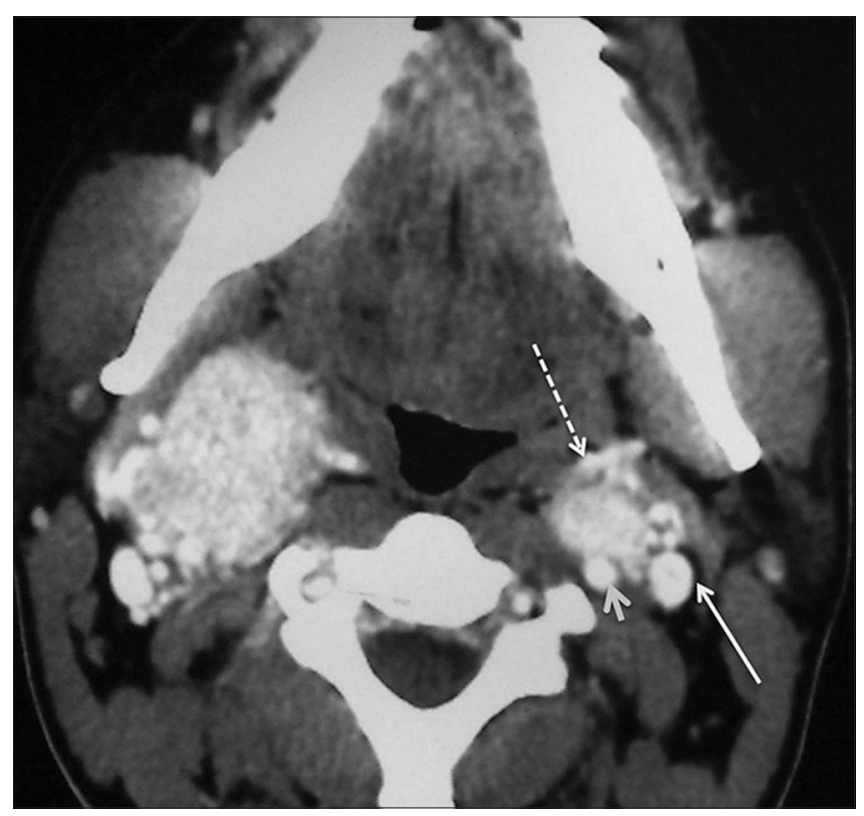

Figure 7: Paragangliomas. Axial contrast-enhanced CT shows striking enhancement in bilateral carotid body tumors (paragangliomas) with splaying of left-sided internal carotid artery (short arrow) and external carotid artery (dashed arrow). Long arrow shows the internal jugular vein

of lymphoma like NK-T cell lymphoma present in extranodal sites like the paranasal sinuses or orbits. ${ }^{[5,6]}$ The involvement of multiple contiguous vertebrae, focal erosion of the mandible, and a large soft tissue mass with epicenter in the carotid space ruled out solitary plasmacytoma of bone.
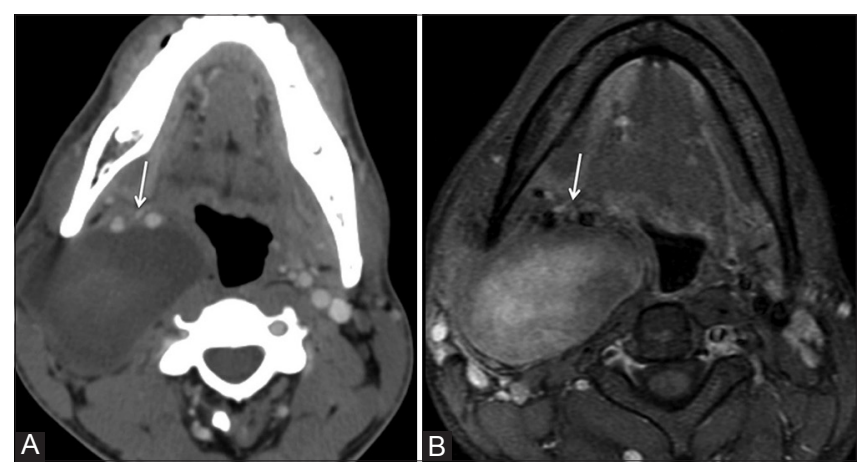

Figure 6 (A and B): Schwannoma. (A) Axial section contrast-enhanced CT shows a very well-defined non-infiltrating mass in the carotid space displacing the carotid sheath anteriorly (arrow). Note, the hypovascular nature of the mass in early phase CT (B) Post-contrast MRI shows delayed central enhancement due to retention of contrast. Arrow shows the displaced carotid sheath

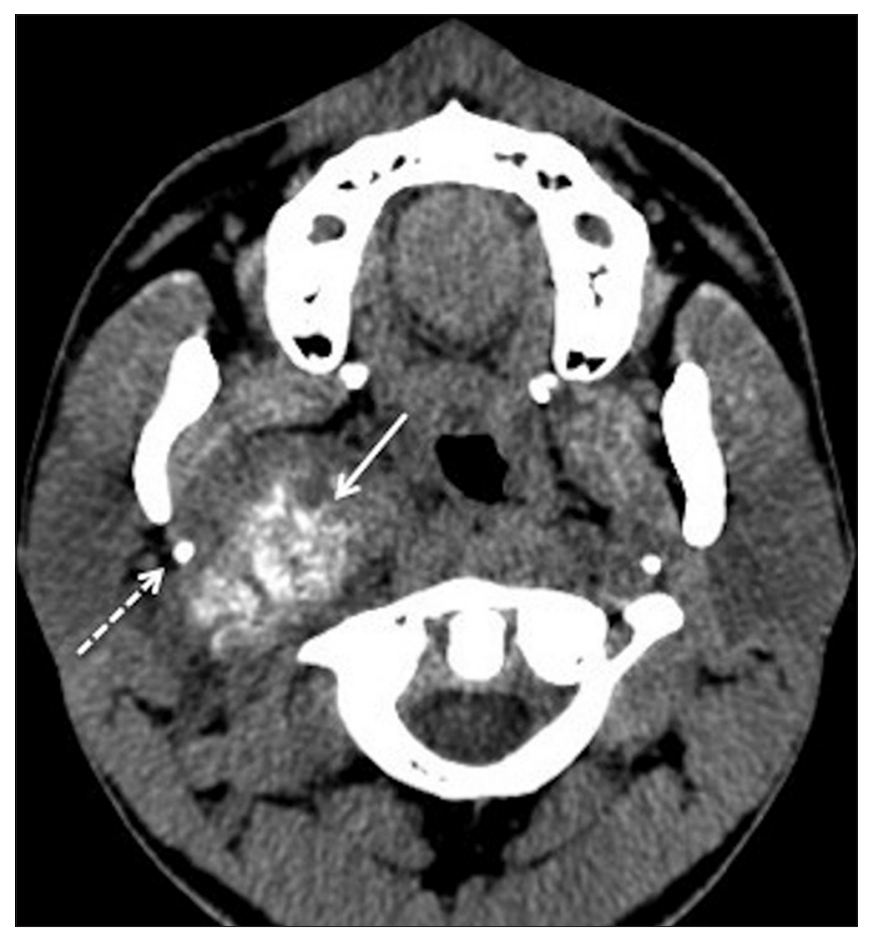

Figure 8: Extracranial meningioma. Axial non-contrast CT shows dense amorphous calcification in an extracranial meningioma in the right carotid space (solid arrow) displacing, but not eroding the right styloid process (dashed arrow)

Reports in literature describe EMPs as mildly heterogeneous soft tissue density masses with moderate-to-marked post-contrast enhancement on CT imaging. ${ }^{[7]}$ On MRI, the tumors are isointense to muscle on T1W images. On $\mathrm{T} 2 \mathrm{~W}$ images, the signal intensity is moderately higher than that of muscle, but lower than that of the mucosa. Moderate-to-marked heterogeneous post-contrast enhancement occurs in all the masses. ${ }^{[7]}$ Ooi et al. also found that aggressive EMPs may be associated with contiguous bone erosions, muscle and fat infiltration, vascular encasement, and regional lymphadenopathy. ${ }^{[7]} \operatorname{Vog}$ et al.$^{[8]}$ also studied the 


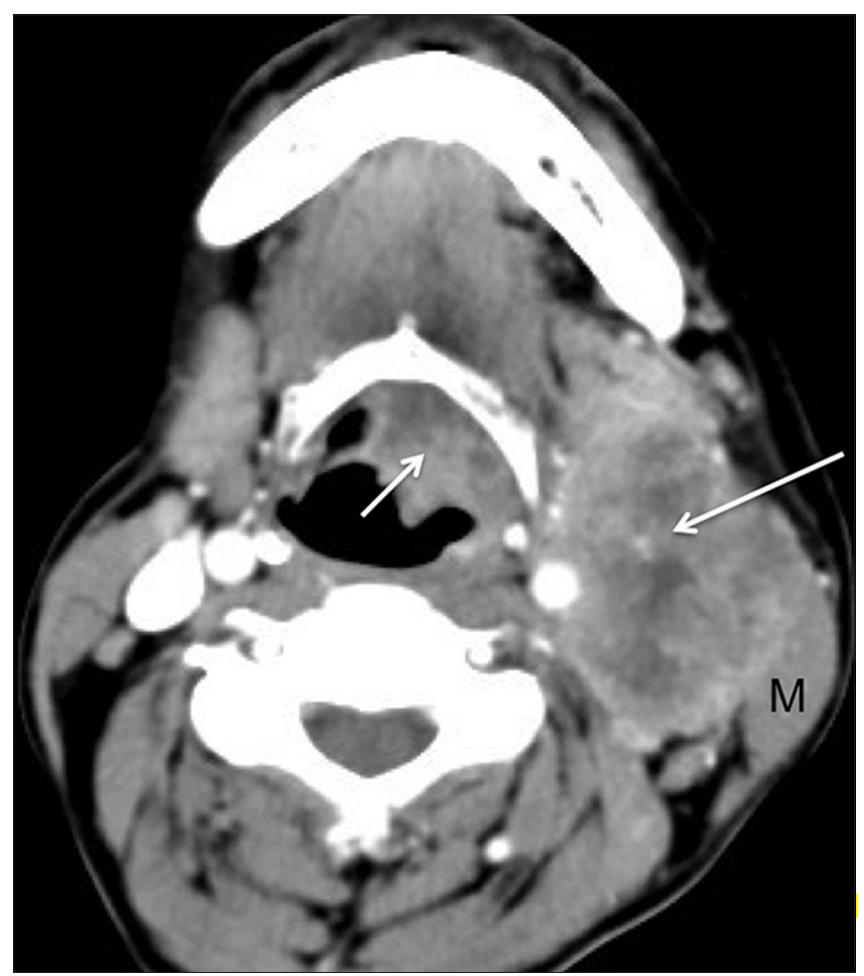

Figure 9: Metastatic node. Axial contrast-enhanced CT shows a primary squamous carcinoma in the left vallecula (short arrow) and a left level II metastatic node (long arrow) that has invaded the sternomastoid muscle (M) and closely abuts the internal carotid artery

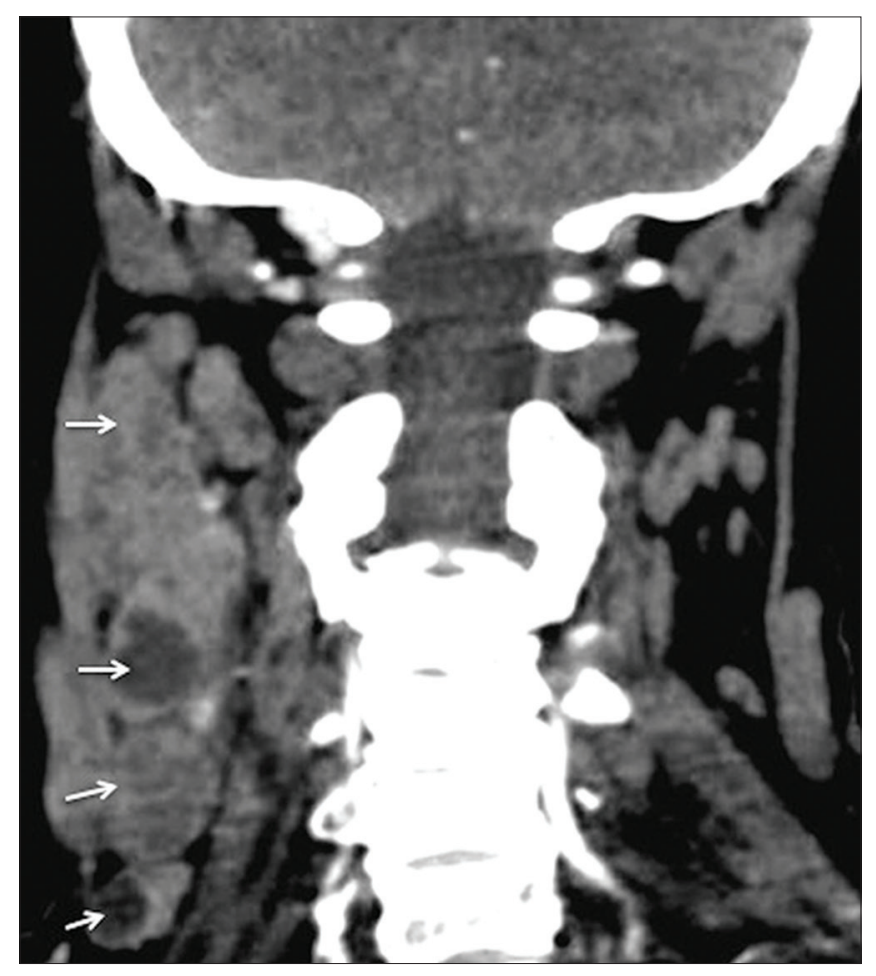

Figure 10: Tuberculous adenopathy. Coronal Multi-detector computed tomography (MDCT) reformation showing multiple necrotic nodes inthe right neck at levels II-IV (arrows). Tuberculous nodes tend to be multiple, necrotic, and can exhibit matting
MRI characteristics of EMPs and found similar results. Our case too displayed a mass in the carotid space with moderate heterogeneous enhancement and associated contiguous bone erosion, muscle infiltration, and vessel encasement. No regional lymphadenopathy was seen in our case.

We hereby infer that in the carotid space, imaging features such as contiguous bone erosion, muscle or vessel infiltration, and adjacent nodal involvement may help rule out the more common aforementioned differential diagnoses and point toward a diagnosis of EMP.

Final diagnosis is with histopathology. Once diagnosed, it is necessary to rule out multiple myeloma by a series of investigations. Primary solitary EMP is managed with radiotherapy, surgery, or both. In our case, the lesion regressed following 4 months of treatment with external beam radiotherapy (55.8 Gy in 31 cycles). This is not unusual as the tumor is very radiosensitive. Response to treatment was assessed on clinical examination. However, new soft tissue lesions developed in the right neck at level IV, in the groin and thigh on the next follow-up visit. Investigations at this stage revealed transformation to multiple myeloma, which was treated with chemotherapy. Long-term monitoring is, therefore, mandatory to detect early local recurrence or conversion to multiple myeloma for obvious therapeutic implications.

\section{References}

1. Clamp JR. Some aspects of the first recorded case of multiple myeloma. Lancet 1967;2:1354-6.

2. International Myeloma Working Group. Criteria for the classification of monoclonal gammopathies, multiple myeloma and related disorders: A report of the International Myeloma Working Group. Br J Haematol 2003;121:749-57.

3. Galieni P, Cavo M, Avvisati G, Pulsoni A, Falbo R, Bonelli MA, et al. Solitary plasmacytoma of bone and extramedullary plasmacytoma: Two different entities? Ann Oncol 1995;6:687-91.

4. Susnerwala SS, Shanks JH, Banerjee SS, Scarffe JH, Farrington WT, Slevin NJ. Extramedullary plasmacytoma of the head and neck region: Clinicopathological correlation in 25 cases. Br J Cancer 1997;75:921-7.

5. Chisin R, Weber AL. Imaging of lymphoma manifestations in the extracranial head and neck region. Leuk Lymphoma 1994;12:177-89.

6. Ooi GC, Chim CS, Liang R, Tsang KW, Kwong YL. Nasal T-cell/ natural killer cell lymphoma: CT and MR imaging features of a new clinicopathologic entity. AJR Am J Roentgenol 2000;174:1141-5.

7. Ooi GC, Chim JC, Au WY, Khong PL. Radiologic manifestations of primary solitary extramedullary and multiple solitary plasmacytomas. AJR Am J Roentgenol 2006;186:821-7.

8. Vogl TJ, Steger W, Grevers G, Balzer J, Mack M, Felix R. MR characteristics of primary extramedullary plasmacytoma in the head and neck. AJNR Am J Neuroradiol 1996;17:1349-54.

Cite this article as: Deshpande SS, Kane S, Arya S. Extramedullary plasmacytoma in the carotid space: Expanding the differential diagnosis. Indian J Radiol Imaging 2014;24:410-4.

Source of Support: Nil, Conflict of Interest: None declared. 